\title{
THE EVALUATION OF AN ECONOMIC DISTANCE AMONG COUNTRIES: A NOVEL APPROACH
}

\author{
Jiří Mazurek*
}

\begin{abstract}
:
The aim of the article is to propose a new measure of a relative economic distance between two countries (RED) or among a group of countries (GRED). Both measures enable to evaluate 'proximity' between national economies through time series of selected variables, and are related to the concept of the sigma (beta) convergence introduced by Barro and Sala-i Martin (1995). In the empirical part of the paper, the RED of Poland, Slovakia, Austria, Germany, the USA and Japan with regard to the Czech Republic are estimated, as well as the time evolution of the GRED of the Czech Republic and its neighbours. The main finding is the strong convergence among these countries after the outbreak of the financial crisis which persists to this day.
\end{abstract}

Keywords: correlation, GDP, unemployment, relative economic distance, the Czech Republic, time series

JEL Classification: C19, F50, 057.

\section{Introduction}

From the early 1990s, empirical studies of economic interdependence among countries began to emerge. Barro (1991) investigated a relationship between economic growth on one side and variables such as initial level of GDP per capita (from 1960), fertility, human capital, political stability on the other side on a set of 98 countries during 1960-1985. He found statistically significant negative correlation between initial level of GDP per capita and economic growth, which can be interpreted in the way that poorer countries grow faster than rich ones, hence converging to each other in the long run.

Furthermore, correlations in nations' economic outcomes were well documented in Elliott (1993) and Chua (1993) and revealed that a country can benefit from the growth of its neighbours. Moreno and Trehan (1997) focused on a relationship between country's location and economic growth and they also found that the growth in one country is positively influenced by the growth of its neighbours. Conley and Ligon (2001) used two measures of economic distance on a set of 18 selected countries. The first measure utilized transportation costs between economies (given as UPS shipping

* Silesian University in Opava, Univerzitní nám. 1934/3, 73340 Karviná, Czech Republic (mazurek@opf.slu.cz). 
rates in US\$), while the second was derived from airlines fares between countries (in US\$). The former measure dealt with physical capital, while the latter with human capital (e.g. transportation costs of an engineer or consultant). Authors found that the closest country to the USA was Germany (171\$) and the most distant South Africa (402\$) using UPS distance, while using the air fare distance the closest country to the USA was the United Kingdom (497\$), while the most distant was South Africa again (1913\$).

However, the general disadvantage of this and similar methods is a dependence on a specific unit (dollar or other), which arises when absolute distance measurement is involved. This can be evaded by the use of a suitable relative scale.

Therefore, the aim of the article is to propose a new measure of a relative economic distance between two countries (RED) and a group relative economic distance (GRED) among at least three countries. Both measures are derived from a correlation between countries' time series of a given macroeconomic indicators and are defined in Section 2.

Generally, economic outcomes across countries are not independent because of international trade and the existence of technological, information, human and physical capital and other spillovers. Correlations between two different countries' variables can be used to evaluate their economic 'distance' or "proximity'. Two countries are closer if their variables correlate stronger, and more distant, when the correlation is weaker. The use of correlation coefficient (which is normalized) leads naturally to a concept of a relative economic distance. Unlike geographic distance, the relative economic distance has following properties:

- It depends on a choice of an indicator used for the evaluation.

- It depends on time period used for the evaluation.

Hence, economic distance is not unique nor stationary in time. Nevertheless, the concept of the economic distance between countries still can be useful on the following grounds:

- It might help to identify countries with the 'closest" economic development to a given country, and subsequently, to an examination of its causes.

- It can be used to estimate the time evolution of a convergence between countries.

- It may allow predicting country's future development from a development of its closest peer(s).

- It can be used to estimate a level of 'economic globalization' within a given group of national economies.

The relative economic distance is closely related to the concept of $\sigma$-convergence and $\beta$-convergence introduced by Barro and Sala-i-Martin (1993). The $\beta$-convergence evaluates a dependence between GDP growth and initial level of GDP, and it was suggested that countries with lower initial level of GDP grow faster than countries with higher initial GDP, so countries converge gradually. The $\sigma$-convergence evaluates the time evolution of a variance in GDP per capita for a set of countries, and it is assumed that due to the aforementioned spillovers countries will subsequently converge to the same level of GDP per capita in the long run. Both $\sigma$ and $\beta$ convergence were found 
in a large number of cross-country empirical studies, see e.g. Abreu (2005), Barro (1991, 1995), Smrčková et al. (2008), Ramirez and Loboguerrero (2002) or Young et al. (2004).

The group relative economic distance applied to a set of three or more countries can be used as a complement to the standard $K O F$ index of globalization (for details see Swiss Federal Institute of Technology, 2010). KOF index measures economic, social and political globalization of individual countries, while the group relative economic distance professes a level of average economic globalization of a group of countries.

The paper is organized as follows: in Section 2 the relative economic distance and the group relative economic distance are introduced, Section 3 provides examples of relative economic distance evaluation followed by a brief discussion of results in Section 4. Conclusions close the article.

\section{A Definition of the Relative Economic Distance and the Group Relative Economic Distance}

In this section measures of the relative economic distance and the group relative distance among national economics are proposed.

Definition 1: Let $A$ and $B$ be two countries of interest, let $f$ be an macroeconomic indicator of interest, let $\tau$ be a time period and let $r$ be the Pearson's correlation coefficient of time series $f_{A}$ and $f_{B}$ for the period $\tau$. Then the relative economic distance (RED) of countries $A$ and $B$ in the indicator ffor the period $\tau$ is given as:

$$
R E D_{f, \tau}(A, B)=\left[\frac{1-r\left(f_{A}, f_{B}\right)}{2}\right] \cdot 100 \% \text {. }
$$

It can be easily verified from (1) that the RED has following properties:

- $R E D_{f, \tau}(A, B) \in[0,100] \%$.

- If a correlation coefficient of time series $f_{\mathrm{A}}$ and $f_{\mathrm{B}} r=1$, then $R E D_{f, t}(A, B)=0 \%$.

- If a correlation coefficient of time series $f_{\mathrm{A}}$ and $f_{\mathrm{B}} r=0$, then $R E D_{f, t}(A, B)=50 \%$.

- If a correlation coefficient of time series $f_{\mathrm{A}}$ and $f_{\mathrm{B}} r=-1$, then $R E D_{f, t}(A, B)=100 \%$.

Many macroeconomic indicators (GDP, unemployment, inflation and others) are correlated among countries with some time lags (ranging from days to years). To incorporate time lags in the RED, Definition 1 can be appropriately modified into the lagged relative economy distance (LRED):

Definition 1b: Let $A$ and $B$ be two countries of interest, let $f$ be an macroeconomic indicator of interest and let $r$ be the Pearson's correlation coefficient of time series $f_{A}$ and $f_{B}$ for periods $\tau_{A}$ and $\tau_{B}$ (of the same length) respectively. Then the lagged relative economic distance (LRED) of countries $A$ and $B$ in the indicator ffor periods $\tau_{A}$ and $\tau_{B}$ is given as: 


$$
\operatorname{LRED}_{f, \tau_{A} \tau_{B}}(A, B)=\left[\frac{1-r\left(f_{A}, f_{B}\right)}{2}\right] \cdot 100 \% \text {. }
$$

However, main difficulty with the interpretation of the LRED measure is the use of different time periods $\tau_{\mathrm{A}}$ and $\tau_{B}$ in the evaluation, so a result cannot be linked to the specific time period (as in the RED).

Definition 2: Let d be a function on a set $X$ so that $d: X \times X \rightarrow \boldsymbol{R}$. Function $d$ is called a distance, if it satisfies the following axioms (1) to (3) and a metric, if it satisfies axioms (1) to (4):

1. $d(x, y) \geq 0$

2. $d(x, y)=0$ if and only if $x=y$

3. $d(x, y)=d(y, x)$,

4. $d(x, z) \leq d(x, y)+d(y, z)$ for all $x, z, y \in X$.

Proposition 1: The function RED given by (1) is a distance, but it is not a metric.

Proof: From the correlation coefficient's properties ( $r$ is symmetric: $r(x, y)=r(y, x)$ and normalized: $-1 \leq r \leq 1)$ it immediately follows that the RED satisfies axioms 1 and 3. Axiom 2 might be violated theoretically, when two time series of two different countries would yield correlation coefficient exactly equal to 1; however, such a coincidence is extremely unlikely when long-time series are involved. The RED is not a metric, as can be demonstrated by an counterexample: consider, for instance, this feasible setting of correlation coefficients among time series of countries $x, y$ and $z: r(x, z)=1, r(x, y)=r(y, z)=-1$. Then invalidity of the $4^{\text {th }}$ axiom from the relation (1) is evident.

The relative economic distance can be extended (generalized) to the group relative economic distance, which expresses a level of 'economic globalization' within a group of countries.

Definition 3: Let $A$ be the set of countries $A=\left\{A_{1}, A_{2}, \ldots A_{n}\right\}$ and let $R E D_{i, j}$ be the relative economic distance between countries $i$ and $j$ in macroeconomic indicator ffor a time period $\tau$. Then the relative economic distance of a group of countries $A$ is given as:

$$
G R E D_{f, \tau}(A)=\frac{\sum_{i=1, i>j}^{n} R E D_{i, j}}{\left(\begin{array}{l}
n \\
2
\end{array}\right)} \cdot 100 \%
$$

Hence, the GRED is estimated simply as the arithmetic mean of all REDs among different countries in the set $A$. Again, $G R E D_{f, \tau}(A) \in[0,100] \%$, and higher values of GRED indicate higher average level of economic proximity within a group. 
With Definitions 1 to 3 some questions arise:

1) Which measure, RED or LRED, is more suitable to the evaluation of the relative economic distance?

2) When evaluating LRED, what time lag in time series should be chosen?

3) Which macroeconomic indicator should be used for the evaluation?

4) What time interval of time series should be used?

Answers to questions 1) and 2) can be provided e.g. by cointegration analysis. The case of potential lags among unemployment rates of the Central European countries was studied for example by Mielcová (2010). According to this study, unemployment rates in the Czech Republic lag unemployment in Poland by two month, while unemployment rates in Austria and Germany lag those in the Czech Republic by one and two months respectively during 1997-2010 period. These findings can be used to for the evaluation of LRED, when unemployment rates are employed.

As for the question 3), the use of a gross domestic product (GDP) growth rates seems to be the best choice because of GDP's fundamental role in macroeconomics, but other indicators such as unemployment rates or inflation can be used, too.

As for the question 4), it seems reasonable to use at least two-year time series for the monthly data and 3-5 year time series for the quarterly data. Hence, both the RED (LRED) and the GRED express a distance among countries during a given period of time regressively.

In the article, quarterly three-year long time series of GDP growth rates are used with the exception of Sections 3.3 and 3.4, where unemployment rates are applied for the evaluation of RED and LRED respectively.

\section{The Evaluation of the RED and the GRED}

To illustrate the evaluation of the RED and the GRED the following estimations were performed:

1) The evaluation of the relative economic distance of Slovakia, Poland, Austria, Germany, the USA and Japan with regard to the Czech Republic with the use of GDP data up to the $3^{\text {rd }}$ quarter of 2010 (Section 3.2).

2) The evaluation of the relative economic distance of Slovakia, Poland, Austria, Germany, the USA and Japan with regard to the Czech Republic with the use of unemployment rates up to the $3^{\text {rd }}$ quarter of 2010 (Section 3.3).

3) The evaluation of the relative economic distance of the Czech Republic and Germany with the use of lagged unemployment rates from previous section (Section 3.4).

4) The evaluation of the time evolution of the RED between the Czech Republic and the Slovak Republic during 1997-2010 with the use of GDP data (Section 3.5). 
5) The evaluation of the time evolution of the $\operatorname{GRED}(A)$, where $\mathrm{A}=\{$ Austria, the Czech Republic, Germany, Poland and the Slovak Republic $\}$ during 1997-2010 period with the use of GDP data (Section 3.6).

As for the selection of countries, neighbours of the Czech Republic were chosen along with the USA and Japan in cases 1) and 2). The selection of the USA and Japan was based on several reasons:

1. Both countries are geographically distant from the Central Europe, so it might be interesting to compare their relative economic distance to the Czech Republic.

2. There is not insignificant trade among the Czech Republic and the USA, the USA are currently the $14^{\text {th }}$ largest international trade partner of the Czech Republic; while Japan is the $15^{\text {th }}$ largest trade partner (Czech Statistical Office, 2009).

3. The US and Japan economies are the $1^{\text {st }}$ and the $3^{\text {rd }}$ world's largest economies with worldwide influence.

Furthermore, in cases 1) and 2), the RED was evaluated with the use of the most up-todate data on GDP and unemployment, so it can be considered the relative economic distance at present.

In cases 3) and 4) the RED and the GRED was evaluated with the use of time series of GDP growth rates beginning in 1997, shortly after the Czech and Slovak independent states were constituted; hence it describes the time evolution of the relative economic distance in the last 13 years.

\subsection{The data and data sources}

For the evaluation the following time series (adjusted for inflation and seasonality in the case of GDP growth rates) were used:

- quarterly percentage GDP growth rates from the $2^{\text {nd }}$ quarter of 1997 (the earliest data available for all countries of interest) to the $3^{\text {rd }}$ quarter of 2010 from the OECD statistic database (OECDStatExtracts, 2010).

- monthly unemployment rates for the past two years (from November 2008 to October 2010) from TradingEconomics (TradingEconomics, 2010).

For a comparison with the RED results the data about turnover of foreign trade (in \%) with respect to the Czech Republic from the Czech Statistical Office (Czech Statistical Office, 2009) were used.

\subsection{The relative economic distance of Slovakia, Poland, Austria, Germany, USA and Japan with regard to the Czech Republic in GDP growth rates}

To this evaluation the Czech Republic's geographic neighbours along with USA and Japan were chosen. For the evaluation the quarterly GDP data from $4^{\text {th }}$ quarter of 2007 to the $3^{\text {rd }}$ quarter of 2010 were selected. 
The comparison of the RED revealed (see Table 1 and Figure 1), that the Slovak' economy was the closest economy to that of the Czech Republic; this result is not surprising as ties between both countries are still strong after split-up of the joint state, the Czechoslovakia, in 1993. Though Poland is the neighbour of the Czech Republic, its relative economic distance was higher than that of geographically distant countries such as Japan or the USA.

Table 1

The Relative Economic Distance RED (in \%) of Six Selected Countries (with regard to the Czech Republic evaluated from the quarterly GDP growth rates from Q4-2007 to Q3-2010)

\begin{tabular}{|l|c|c|}
\hline Country & Pearson's r. & RED (\%) \\
\hline Slovakia & 0,865 & 7 \\
\hline Germany & 0,793 & 10 \\
\hline Austria & 0,777 & 11 \\
\hline USA & 0,755 & 12 \\
\hline Japan & 0,692 & 15 \\
\hline Poland & 0,525 & 24 \\
\hline
\end{tabular}

Figure 1

A Graphical Comparison of Relative Economic Distance RED (in \%) of Six Selected Countries (with regard to the Czech Republic evaluated from the quarterly GDP growth rates from Q4-2007 to Q3-2010)

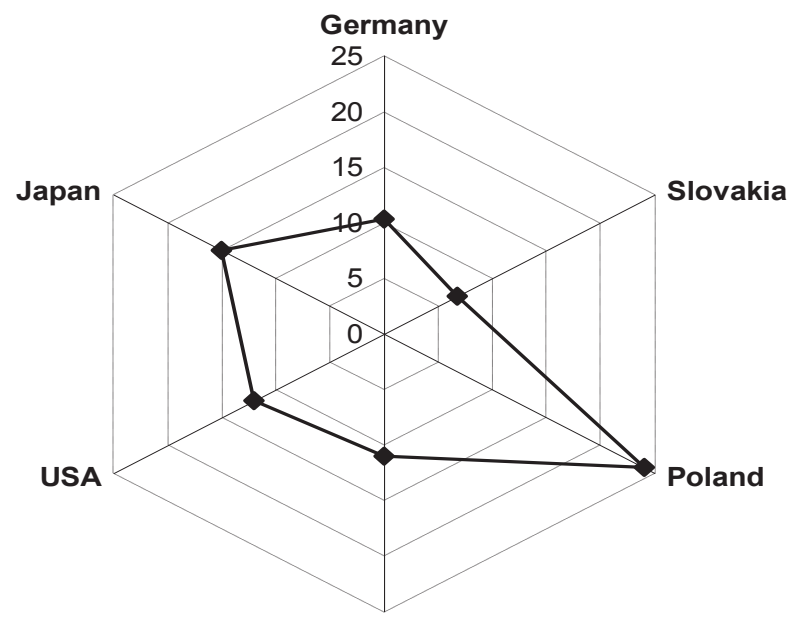

Austria 


\subsection{The relative economic distance of Slovakia, Poland, Austria, Germany, the} USA and Japan with regard to the Czech Republic in unemployment rates

When the evaluation parameter changes from quarterly GDP growth rates to the monthly unemployment rates for the past two years (from November 2008 to October 2010), results will inevitably change. Under new circumstances, the closest country to the Czech Republic is Poland and the furthermost is Germany (see Table 2 and Figure 2).

Table 2

The Relative Economic Distance RED (in \%) of Six Selected Countries (with regard to the Czech Republic evaluated from the monthly unemployment rates from November 2008 to October 2010)

\begin{tabular}{|l|c|c|}
\hline Country & Pearson's r. & RED (\%) \\
\hline Poland & 0,945 & 3 \\
\hline USA & 0,926 & 4 \\
\hline Japan & 0,768 & 12 \\
\hline Slovakia & 0,526 & 24 \\
\hline Austria & 0,478 & 26 \\
\hline Germany & 0,295 & 35 \\
\hline
\end{tabular}

Figure 2

A Graphical Comparison of Relative Economic Distance RED (in \%) of Six Selected Countries (with regard to the Czech Republic evaluated from the monthly unemployment rates from November 2008 to October 2010)

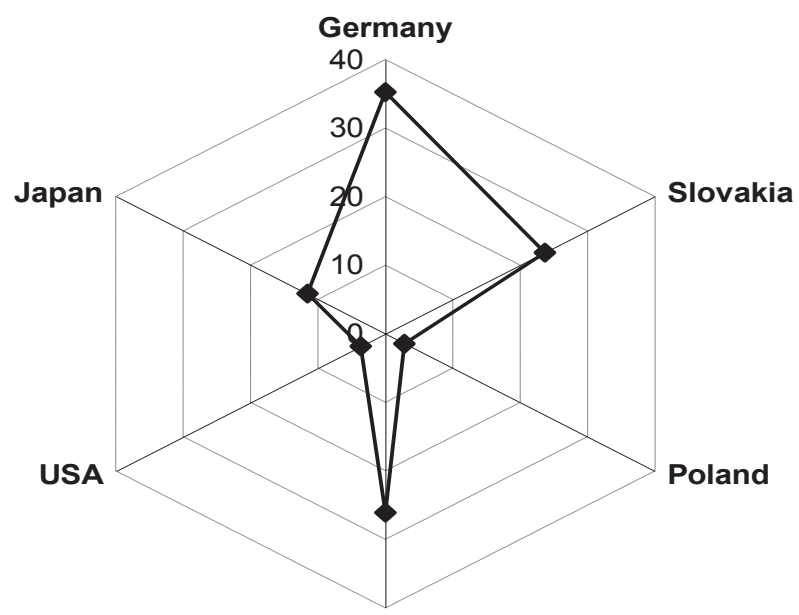

Austria 


\subsection{The lagged relative economic distance between the Czech Republic and Germany in unemployment rates}

For a demonstration of the evaluation of the lagged relative economic distance (LRED), the Czech Republic and Germany were chosen along with the unemployment rates as the macroeconomic indicator. Results are shown in Table 3. As can be seen, the LRED achieved its maximum value (35\%) with no lag in both time series, and minimum value of $10 \%$ was with the lag of 6 month (Germany's rates preceded the Czech's). This result can be interpreted so that the Czech unemployment is the most sensitive to the change of unemployment in Germany after six months (in this particular case).

Instead of considering different LREDs for various time lags, only one LRED can be taken into account by reduction of LRED results to its minimum value over all feasible time lags.

Table 3.

The Evaluation of the Lagged Relative Economic Distance (LRED) Based on Unemployment Rates among the Czech Republic and Germany

\begin{tabular}{|c|l|l|c|c|}
\hline Lag (in months) & \multicolumn{1}{|c|}{$\mathbf{T}(\mathbf{G E R})$} & \multicolumn{1}{|c|}{$\mathbf{T}(\mathrm{CZE})$} & $\boldsymbol{r}$ & LRED (in \%) \\
\hline $\mathbf{0}$ & $11 / 2008-10 / 2010$ & $11 / 2008-10 / 2010$ & 0.295 & 35 \\
\hline $\mathbf{1}$ & $11 / 2008-9 / 2010$ & $12 / 2008-10 / 2010$ & 0.439 & 28 \\
\hline $\mathbf{2}$ & $11 / 2008-8 / 2010$ & $1 / 2009-10 / 2010$ & 0.493 & 25 \\
\hline $\mathbf{3}$ & $11 / 2008-7 / 2010$ & $2 / 2009-10 / 2010$ & 0.557 & 22 \\
\hline $\mathbf{4}$ & $11 / 2008-6 / 2010$ & $3 / 2009-10 / 2010$ & 0.627 & 19 \\
\hline $\mathbf{5}$ & $11 / 2008-5 / 2010$ & $4 / 2009-10 / 2010$ & 0.735 & 13 \\
\hline $\mathbf{6}$ & $11 / 2008-4 / 2010$ & $5 / 2009-10 / 2010$ & 0.798 & 10 \\
\hline $\mathbf{7}$ & $11 / 2008-3 / 2010$ & $6 / 2009-10 / 2010$ & 0.781 & 11 \\
\hline $\mathbf{8}$ & $11 / 2008-2 / 2010$ & $7 / 2009-10 / 2010$ & 0.712 & 14 \\
\hline
\end{tabular}

\subsection{The evaluation of the time evolution of the RED between the Czech Republic and the Slovak Republic}

For the evaluation of time development of RED between the Czech and Slovak Republics quarterly percentage GDP growth rates from $2^{\text {nd }}$ quarter of 1997 to the $3^{\text {rd }}$ quarter of 2010 from the OECD database were used, and are presented in Figure 3. The relative economic distance between both countries is shown in Figure 4. The RED presented in the $1^{\text {st }}$ quarter of 2000 (at the beginning of the graph in Figure 4) was calculated from quarterly GDP growth rates spanning from the $2^{\text {nd }}$ quarter of 1997 to the $1^{\text {st }}$ quarter of 2000 , and the same procedure of correlating through the last 12 quarters was applied to the following quarters (hence, the RED forms a kind of 'moving' distance). 
As can be seen from Figure 4, both economies are converging to each other in the recent years, but during 2006-2007 period the divergence occurred, as Slovak's economy was accelerating, while the Czech's economy began to decline at the same time.

Figure 3

Quarterly Percentage Changes in Real GDP from the Preceding (quarter-to-quarter) Period, the Czech Republic and the Slovak Republic, 1997-2010

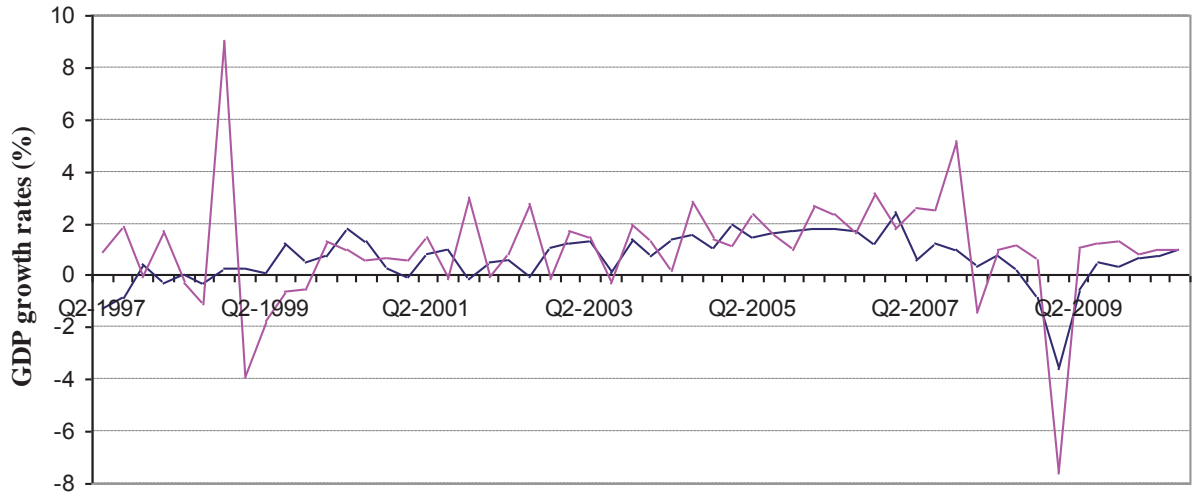

quarter-year

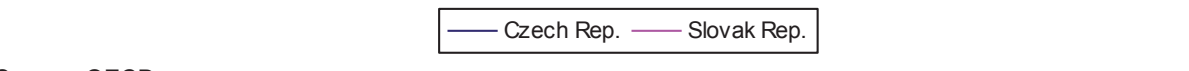

Source: OECD.

Figure 4

The Time Evolution of the Relative Economic Distance between the Czech Republic and the Slovak Republic (RED was evaluated 3-years regressively to the date presented on the $x$ axis)

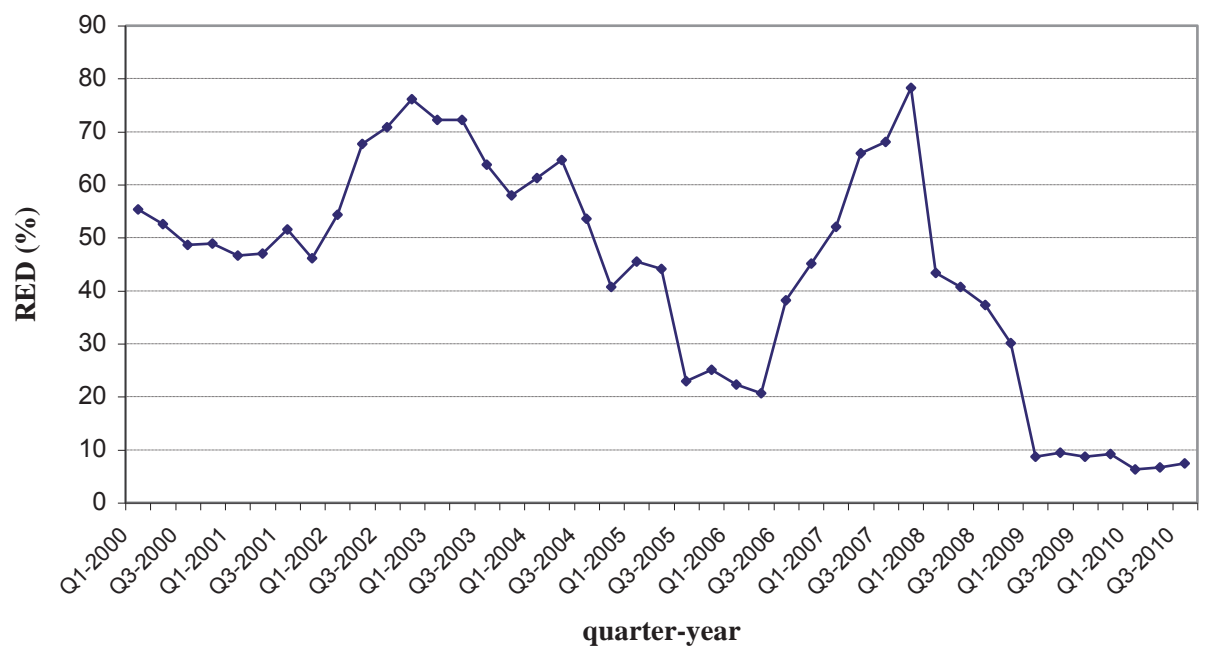




\subsection{The evaluation of the time evolution of the GRED of the Czech Republic and its neighbours}

This last subsection provides the evaluation of the group relative economic distance among the Czech Republic and its four neighbour economies with the use of the same GDP data as in Subsection 3.4. The result is shown in Figure 5. From 2000 to 2008 there is a mild downward trend in the RED, with a sharp decline after 2008, indicating that the Czech Republic's and its neighbours' economies began to converge in 2006, shortly before the global financial crisis broke out, and the convergence is still in progress during 2010.

Figure 5

The Time Evolution of the Group Relative Economic Distance among the Czech Republic, Austria, Germany, Poland and the Slovak Republic

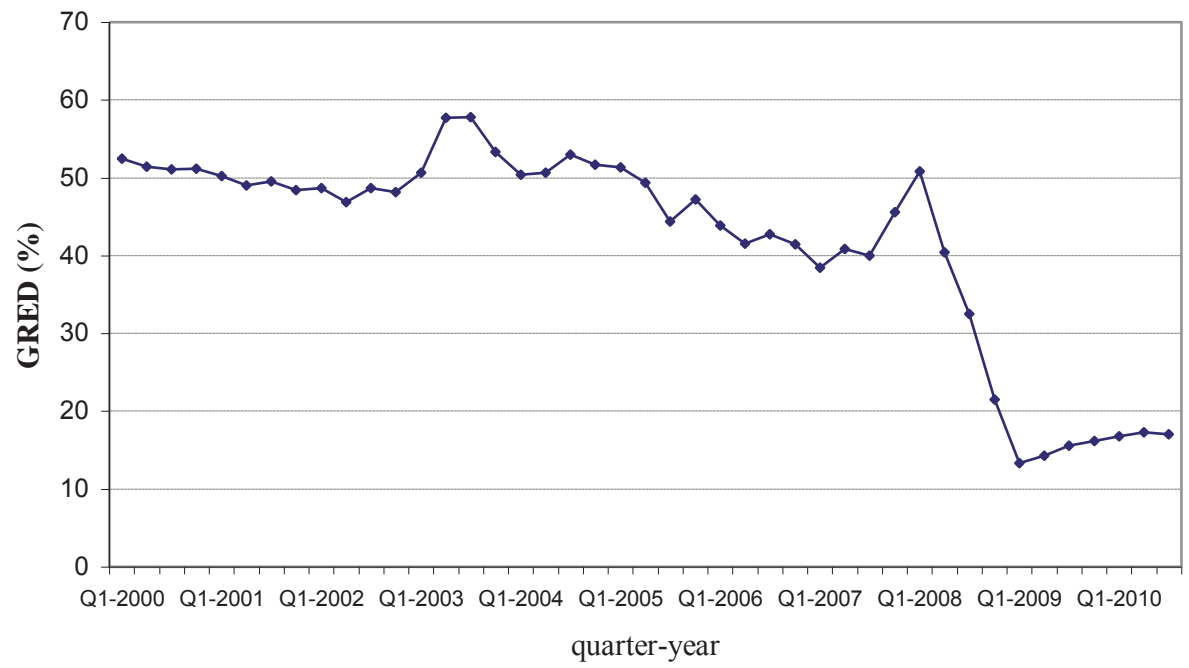

Note: The GRED was evaluated during a 12 quarter-long moving period. The first point of the graph (at the $1^{\text {st }}$ quarter of 2000) expresses the RED during the $2^{\text {nd }}$ quarter of 1997 to the $1^{\text {st }}$ quarter of 2000.

\section{Discussion of Results}

The relative economic distance of six selected countries with respect to the Czech Republic can be compared with actual geographic distance (estimated as an air distance among capital cities) and turnover of foreign trade of these countries, see Table 4.

When GDP growth rates were used for the RED evaluation, the ranking of countries according to the RED was different than the ranking on the grounds of the geographic distance (GD) and turnover of foreign trade. In the RED, the closest country to the Czech Republic was Slovakia and the most distant Poland. Pearson's correlation coefficient $r=0.11$ indicates no relationship between the RED and GD; hence the RED 
was found independent on the geographic distance in this study. Pearson's correlation coefficient between the RED and the turnover $r=-0.23$ indicates slight but statistically insignificant indirect proportionality of both variables.

When unemployment rates were used for the RED evaluation, also the ranking of countries according to the RED was different than the ranking on the grounds of the geographic distance and turnover. The closest country to the Czech Republic was Poland and the most distant Germany. Pearson's correlation coefficient between the RED and GD $r=-0.52$ and correlation coefficient between the RED and the turnover $r=0.70$ are rather high, but are not statistically significant at $\alpha=0.05$ level due to small sample of countries. To draw statistically more significant conclusions, the sample of countries had to be enlarged.

As for RED's dynamics, the relative economic distance of the Czech Republic and its neighbours was fluctuating slightly between $40-60 \%$ values in the early 2000 s (see Figure 5), but with the outbreak of the financial crisis in 2008 the RED began to fall approximately to $15 \%$, as countries in the Central Europe experienced similar economic decline with GDP growth rates close to zero or decreasing by a few percent quarterly until late 2009 .

Table 4

Geographic Distance and Turnover of Foreign Trade of Selected Countries with regard to the Czech Republic

\begin{tabular}{|l|c|c|c|c|}
\hline Country & $\begin{array}{c}\text { Geographic } \\
\text { distance } \mathbf{( k m )}\end{array}$ & $\begin{array}{c}\text { Turnover } \\
\text { (in \%) }\end{array}$ & $\begin{array}{c}\text { RED } \\
\text { (GDP) }\end{array}$ & $\begin{array}{c}\text { RED } \\
\text { (uenmployment) }\end{array}$ \\
\hline Austria & 248 & 4 & 11 & 26 \\
\hline Germany & 278 & 29 & 10 & 35 \\
\hline Slovakia & 351 & 7 & 7 & 24 \\
\hline Poland & 512 & 6 & 24 & 3 \\
\hline USA & 6551 & 2 & 12 & 4 \\
\hline Japan & 9104 & 2 & 15 & 12 \\
\hline
\end{tabular}

Source of turnover of foreign trade data: the Czech Statistical Office.

\section{Conclusions}

In the globalized world a geographic distance among countries is not so important as it was in the past. Many countries divided by thousands of miles may be close to each other in economics, culture, education, technology or in access to information via Internet.

The article presents the new concept of the relative economic distance of two or more countries. The relative economic distance is derived from correlations between time series of selected countries in a given macroeconomic indicator. Unlike geographic 
distance, the relative economic distance depends on a choice of a macroeconomic parameter and time period used for an evaluation. However, it can still be useful, as it allows evaluating proximity between two countries' economies or even economies of a group of countries, and their evolution in time. In the former case, it is conceptually related to the $\sigma$-convergence, in the latter case, it might represent a measure of an 'economic globalization' of the group and thus form a complement to the standard KOF index of globalization.

In the empirical part of the paper, the relative economic distance of six countries (Austria, Germany, Japan, Poland, Slovakia and the USA) with regard to the Czech Republic was evaluated using quarterly GDP growth rates for the past three years and monthly unemployment rates during past two years. In the former case, the closest economy of the Czech Republic was Slovak's and the most distant Polish, in the latter case the closest was Polish economy and the most distant that of Germany. However, these results were influenced by (then ongoing) financial crisis. Also, potential statistical relationships between the RED and foreign trade and geographic distance were examined, but due to a small sample of countries these findings were not statistically significant. Nevertheless, they can be established by future research.

Time evaluation of relative economic distance of the Czech Republic and its four neighbours during 1997-2010 revealed the strong convergence within the group beginning in 2006 and lasting through 2010; the Czech and Slovak economies converged to each other during the same period as well. The cause of these findings might be largely attributed to the recent global financial crisis, for many national economies experienced similar development (economic decline) after the crisis broke out in the summer 2007.

\section{References:}

Abreu, M. et al. (2005), "Space and Growth: a Survey of Empirical Evidence and Methods." Région et Développement 21, 2005, pp. 13-44.

Barro, R. J. (1991), "Economic Growth in a Cross Section of Countries." Quarterly Journal of Economics 106, 1991, pp. 407-444.

Barro R. J., Sala-i-Martin, X. (1995), Economic Growth. McGraw-Hill, 1995.

Chua, H. B. (1993), "Regional Spillovers and Economic Growth“. 1993. Manuscript.

Conley, T. G., Ligon, E. (2001), "Economic Distance and Cross-country Spillovers." Journal of Economic Growth, 2001, Vol. 7, Nr. 2, pp. 157-187.

Czech Statistical Office. (2009). http://www.czso.cz/csu/2010edicniplan.nsf/p/6008-10

Elliott, G. (1993). "Spatial Correlation and Cross Country Regressions". Manuscript.

Mielcová, E. (2010). "Cointegration Analysis of the Unemployment Rate Time Series - the Case of the Czech Republic, Slovakia, Poland, Austria, and Germany 1997-2009." In: Mathematical Methods in Economics - Proceedings, Č. Budějovice.

Moreno, R., Trehan, B. (1997) "Location and the Growth of Nations." Journal of economic growth, vol. 2, 1997, pp. 399-418.

OECDStatExtracts (2010) http://stats.oecd.org. 
Ramírez, M. T., Loboguerrero, A. M. (2002), "Spatial Dependence and Economic Growth: Evidence from a Panel of Countries." Available at: http://www.webmeets.com/files/papers/lacea/2002 /115/ Growth-Spatial\%20may.pdf.

Smrčková, G., Vlček, I., Cengroš, F. (2008), "Reálná konvergence - souvislosti a příčiny." Ministerstvo financí ČR, výzkumná studie č. 3/2008. Available at: http://www.mfcr.cz /cps/rde/ xchg/mfcr/xsl/makr_vyzkum_studie.html.

Swiss Federal Institute of Technology (2010), http://globalization.kof.ethz.ch/

TradingEconomics (2010), http://www.tradingeconomics.com.

Young, A. T., Higgins, M. J., Levy, D. (2004), "Sigma-Convergence Versus Beta- Convergence: Evidence from U.S. County-Level Data." Available at: http://www.eabcn.org /research/ documents/levy_sigma_convergence.pdf. 